\title{
Comparative efficacy of sodium lactate and Natamycin against discoloration and spoilage of fresh beef during chilled storage
}

\author{
Xinhui WANG ${ }^{1_{+}}$(D), Yue DING ${ }^{1}$, Tian TIAN ${ }^{2+}$, Yang LIU ${ }^{1}$
}

\begin{abstract}
Comparative efficacy of sodium lactate and Natamycin as preservative against discoloration and spoilage of fresh beef stored at $4{ }^{\circ} \mathrm{C}$ were evaluated. Fresh beef was treated with $3 \mathrm{~g} / \mathrm{L}$ sodium lactate and Natamycin, respectively, and sterilized physiological saline was used as negative control. The spoilage of beef samples was monitored by $\mathrm{pH}$, total volatile basic nitrogen (TVB-N), discoloration, sensory analysis and bacterial quality which were determined by culture-dependent and culture-independent analyses. The acceptable shelf life of fresh beef treated by sodium lactate and Natamycin reached 6 days and 4 days, respectively. Whereas, the control sample was acceptable for 3 days. The two kinds of preservative were conducive to hygiene levels improvement. Lactobacillus spp. and Weissella spp. sharply displaced the Ralstoni spp. with high potential spoilage and became the predominant bacteria, and the proliferation of Serratia spp. as the representatives' genus of psychrotrophic Enterobacteriaceae were completely controlled in the preservative treated samples. Sodium lactate displayed a remarkable efficacy against discoloration and spoilage of chilled beef, resulting in shelf life extension by 3-4 days. Natamycin has a remarkable antibacterial efficacy but a little efficacy against discoloration. Thus, sodium lactate is more suitable for freshness promotion of chilled beef.
\end{abstract}

Keywords: chilled beef; high-throughput sequencing; natamycin; sodium lactate; shelf life.

Practical Application: Chilled beef is the most common types of raw beef on the market. However, meat structure and biochemistry undergone significant changes such as tenderness and color along with storage, resulting in losses in quality and perceived value. As a result, the way to extend shelf life of chilled beef and retain better quality is of great importance for both customers and meat industries. In this study, sodium lactate and Natamycin as preservation treatment was used in chilled beef and comparative efficacy of sodium lactate and Natamycin against discoloration and spoilage was systematically evaluated. Sodium lactate displayed a remarkable efficacy against discoloration and spoilage of chilled beef, resulting in shelf life extension by 3-4 days. Natamycin has a remarkable antibacterial efficacy but a little efficacy against discoloration. Thus, sodium lactate is more suitable to be applied for freshness promotion of chilled beef.

\section{Introduction}

Fresh beef is favored by the customers for its good taste and abundant nutrients, which is a large part of the human diet in many countries and a great part of the food industry. Due to the influence of both enzymatic and microbial reactions, fresh beef is highly perishable and has quite short storage life postmortem under chilled storage $\left(4-5^{\circ} \mathrm{C}\right)$ (Magrinyà et al., 2015). Spoilage of raw beef during production and sales will result in a waste problem and potential microbial safety hazards for the public health (Yang et al., 2017). Consequently, the food safety and food transportation efficiency of fresh beef is of major concern to consumers and meat industries. Thus, the way to extend beef shelf life is of great importance for both customers and meat industries. Discoloration and microbial growth are primarily responsible for unacceptable and spoilage, resulting in a short shelf-life and severe retail waste (Yang et al., 2018). As a result, the efficacy of preservation technology for controlling color stability and microbial growth, especially for spoilage and pathogenic microorganisms, is critical capability for freshness and shelf life extension of fresh beef.

To date, various physical preservation technologies, such as modified atmosphere packaging (MAP) and irradiation treatment for controlling temperature, humidity, air quality, radiation, and pressure is widely used in meat aquatic products to control the quality (Zhang et al., 2017). Although these methods display high safety, complicated procedures are especially required in practical applications. Recently, preservatives have aroused much attention in quality control of meat. Chemical preservatives such as salts are extensively applied in meat production such as sausages and bacon, but it is not suitable for fresh meat preservation. Furthermore, salts may bring some potential risks to customers, especially for patients with hypertension. Therefore, it is essential to further explore bio-preservatives which meet food safety and are suitable for fresh meat preservation. 
Sodium lactate $\left(\mathrm{C}_{3} \mathrm{H}_{5} \mathrm{NaO}_{3}, \mathrm{MW}=112.06\right)$, is a salt of lactate that exists widely in nature. It has been reported that sodium lactate can successfully inhibit several microorganisms, such as Salmonella spp., and Pseudomonas spp. (Choi \& Chin, 2003). Moreover, sodium lactate displays color preservation on fresh meat. Natamycin has been recognized as an effective bio-preservative with a good antiseptic effect which has a broad spectrum of antimicrobial activity. Both sodium salt and Natamycin have been approved by Food and Drug Administration (FDA) as a safe food addictive used in meat (Magrinyà et al., 2015). Although successful applications of sodium salt or Natamycin in meat products shelf life extension are available, few systematic studies have been concentrated on fresh beef quality enhancement and comparative efficacy on shelf life extension, color preservation and antimicrobial activity between sodium salt and Natamycin in fresh beef under chilled storage.

Discoloration and uncontrolled bacterial growth are responsible for the short shelf life of fresh beef under chilled storage. Therefore, in this study, sodium salt and Natamycin as preservation treatment were used in fresh beef under chilled storage, compared with the control treated with sterilized physiological saline. The relationship between shelf life extension and color preservation and antimicrobial activity enhanced by the two kinds of preservation treatment was systematically evaluated. Furthermore, efficacy of sodium lactate and Natamycin on maintaining freshness was compared to further exploit their preservation efficacy.

Spoilage was monitored by $\mathrm{pH}$, total volatile basic nitrogen (TVB-N), discoloration, sensory analysis and bacterial quality. Discoloration was detected by colorimetric evaluation combined with consumer-defined color acceptability. Microbial quality was evaluated by five principal microbiological indicators determined by culture-dependent method, namely Total viable counts (TVC) and Lactic acid bacterial (LAB) counts, Brochothrix spp. counts, Pseudomonas spp. counts and Enterobacteriaceae counts, combined with bacterial community dynamics determined by high-throughput sequencing technology.

\section{Materials and methods}

\subsection{Beef sample collection and treatments}

Fresh beef loins (Qinchuan cattle) were purchased from a local market of agricultural products located in Chengdu, Sichuan Province, China. After purchasing, the beef loins were immediately kept in an insulation ice box under $0-4{ }^{\circ} \mathrm{C}$ and transported to laboratory within 15 minutes. After transportation to the laboratory, beef loins were individually cut into 96 cuts $(10 \mathrm{~cm} \times 10 \mathrm{~cm} \times 1.5 \mathrm{~cm})$ with about $100 \mathrm{~g}$ under chilled conditions $\left(0-4{ }^{\circ} \mathrm{C}\right)$. Subsequently, all cuts were equally divided into three groups for experiments. Two types of preservatives were prepared, namely Group SL (3 g/L sodium lactate) and Group NA ( $3 \mathrm{~g} / \mathrm{L}$ Natamycin). Then two groups of beef samples dipped into above two preservation solutions for $3 \mathrm{~min}$, respectively, and then drained for $1 \mathrm{~min}$. Correspondingly, the control group labeled as Group C was treated with sterilized physiological saline. After treatment, all samples were immediately packaged with polyethylene sterile bags and stored at $4 \pm 1^{\circ} \mathrm{C}$ for 7 days.
Samples were sampled in triplicate for physiochemical analyses and sensory evaluation every day, and for microbiological examination on day $0,3,5$ and 7 .

\subsection{Physicochemical analyses}

$\mathrm{pH}$ values of beef samples were determined by using a $\mathrm{pH}$ meter (Testo 205, Testo International Trade (Shenzhen) Co., Ltd., Shenzhen, China) with automatic temperature compensation (NTC) electrode according to the method described as Wang et al. (2015a). Inserting the electrode directly into beef samples, triplicate readings were obtained from three different random locations and then averaged.

Total volatile basic nitrogen (TVB-N) content was determined using a steam distillation method according to the Chinese National Food safety standard methods GB 5009.228-2016 described as Chen et al. (2019).

The surface color of beef samples was measured by using a colorimeter (CS-22, Hangzhou CHNSpec Technology Co. Ltd, Hangzhou, China) according to the method described as Wang et al. (2015b). Lightness $\left(\mathrm{L}^{*}\right)$, redness $\left(\mathrm{a}^{*}\right)$ and yellowness $\left(b^{\star}\right)$ were determined at three random locations on each sample and then triplicate readings were averaged.

\subsection{Sensory analyses}

At each storage time, the freshness of beef samples was assessed by human sensory analyses according to the method described by Chen et al. (2020). All samples were coded with three digit numbers and presented to 11 sensory panelists who have been trained according to in a random order. Sensory panelists evaluated the freshness of beef samples according to their organoleptic characteristics, namely color, odor, texture, appearance and viscosity, using a 5-point scale based on attribute degrees as shown in Table S1 of Supplementary Material.

\subsection{Bacterial counts}

Microbial quality in beef samples was monitored by culture-dependent method based on plate counts. Total viable counts (TVC), lactic acid bacteria (LAB) counts, Pseudomonas spp. counts, Bronchothrix spp. counts and Enterobacteriaceae counts were performed according to the methods described as Yang et al. (2017). Briefly, at each sampling date, $10 \mathrm{~g}$ of sample was aseptically removed into stomacher bags containing $90 \mathrm{~mL}$ sterile $0.1 \%$ peptone water, and then was mixed in a blender. After mixing, a 10-fold dilution series was used for microbiological analysis. TVC and LAB counts were enumerated on plate count agar (PCA, Sangon Biotech Co. Ltd, Shanghai, China) and De Man, Rogosa, Sharpe Agar (MRS, Sangon Biotech Co. Ltd, Shanghai, China), respectively, which were all incubated at $37^{\circ} \mathrm{C}$ for 48 h. Pseudomonas selective Agar (Sangon Biotech Co. Ltd, Shanghai, China) and Steptomycin Thallous Acetate Agar (STAA, Shandong Tuopu Biological Engineering Co., Ltd., Shandong, China) were applied for Pseudomonas spp. counts and Bronchothrix spp. counts, respectively, which were all incubated at $25^{\circ} \mathrm{C}$ for $48 \mathrm{~h}$. Enterobacteriaceae was determined on Violet Red Bile Glucose Agar (VRBGA, Shandong Tuopu Biological 
Engineering Co., Ltd., Shandong, China) with incubation at $37^{\circ} \mathrm{C} 24 \mathrm{~h}$. The results were expressed as $\log _{10} \mathrm{CFU} / \mathrm{g}$ sample.

\subsection{Bacterial community analyses by High-throughput sequencing}

The extraction of total genomic DNA of the bacteria collected from the beef samples was conducted according to previous method as described by Liu et al. (2018) and Wang et al. (2017). The bacterial DNA of samples was extracted using the E.Z.N.ATM Mag-bind Soil (OMEGA, USA) according to the manufacturer's instructions. The DNA concentration was measured using BioSpec-nano (Shimadzu, Japan) and the DNA quality was confirmed by $0.8 \%$ agarose gel electrophoresis.

PCR amplifications of the V4 region of bacterial 16S rRNA gene were implemented with the primer pairs 515F (5'-GTGCCAGCMGCCGCGGTAA-3') and 806R (5'-GGACTACHVGGGTWTCTAAT-3'). The systems and conditions of PCR amplification were performed according to previous method as described by Wang et al. (2018). After amplification, the PCR products were sequenced by the highthroughput sequencing technology on the llumina MiSeq platform (Beijing Novogene Technology Co. Ltd, Beijing, China).

After high-throughput sequencing, the raw sequencing data were merged and screened as previously described (Chen et al., 2019; Wang et al., 2019), and then the sequences with high quality were clustered and regarded as operational clustering method (OTUs) based on the SILVA reference gene database (Quast et al., 2013; Edgar, 2010) at an identity threshold of 97\%. The Alpha diversity was assessed to identify bacterial community richness based on Chao 1 and Abundance-based coverage (ACE), diversity based on Shannon and Simpson indices, and sequencing depth based on Good's coverage. All these indices were calculated using the QIIME software (Version 1.7.0).

\subsection{Statistical analyses}

Each test was performed in triplicate and these results were reported by means with standard deviation, except for bacterial enumeration in duplicate. Data were presented as mean values accompanied with the standard deviation. Duncan's multiple range test (significance $\mathrm{p}<0.05$ ) was employed for the independence of error terms using the SPSS Statistics software (IBM, Chicago, Ill., U.S.A.).

\section{Results and discussion}

\subsection{Comparative effects on physicochemical characteristics of chilled beef during storage}

The $\mathrm{pH}$ values in beef samples during storage at $4{ }^{\circ} \mathrm{C}$ are shown in Figure 1a. The initial pH value was 5.47, 5.63 and 5.57 in Group C, Group SL and Group NA, respectively. As storage time extended, the $\mathrm{pH}$ values in Group $\mathrm{C}$ as negative control fluctuated violently, varying from 5.47 to 5.71 . Whereas, the $\mathrm{pH}$ values in Group SL displayed better $\mathrm{pH}$ stability with a range of 5.53 to 5.63 compared with Group NA, which were within the normal range during the storage. The $\mathrm{pH}$ value plays a critical
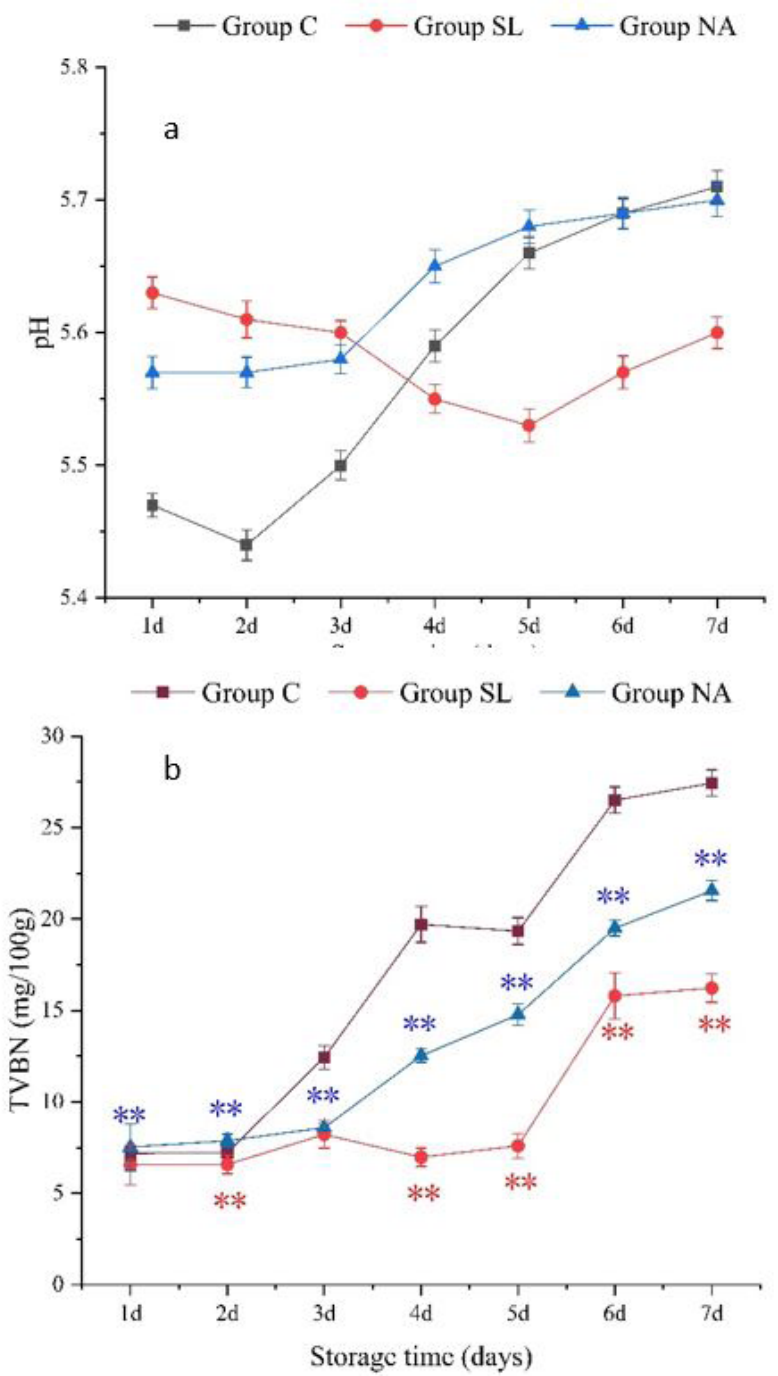

Fig. 1. Comparative effects between sodium lactate and Natamycin on $\mathrm{pH}$ values (a) and total volatile basic nitrogen (TVB-N) levels (b) of chilled beef during storage at $4^{\circ} \mathrm{C}$ for 7 days.

role in raw beef quality during storage, which can affect color appearance the water holding capacity and bacterial growth (Mancini et al., 2010). In this study, the $\mathrm{pH}$ values in the control were from 5.47 to 5.50 in the first 3 days, showing a lower value than preservative treatment. The low $\mathrm{pH}$ value displays a negative effect on color characteristics of beef due to the transition of the easily oxidized $\mathrm{Mb}$ fraction into MetMb, resulting in a darker red color. Moreover, the $\mathrm{pH}$ value in the control with a range of 5.47 to 5.50 was close to isoelectric point (5.2-5.5) of protein in the first 3 days, resulting in a weak water holding capacity. Whereas, in the late 4 days, the $\mathrm{pH}$ value in the control was higher than that of the beef treated by preservatives and increased to 5.71 on the $7^{\text {th }}$ day, which was perhaps attributed to the alkaline substances from protein breakdown. As a result, any deviations from the norm in terms of $\mathrm{pH}$ will affect color intensity, water holding capacity and spoilage. These results revealed that sodium lactate and Natamycin as preservative contributed to $\mathrm{pH}$ stabilization, resulting in quality improvement of chilled beef. These results 
were in line with those results reported by Sallam \& Samejima (2004) and Liu et al. (2020), who found that sodium lactate and Natamycin were conducive to $\mathrm{pH}$ stabilization for chilled beef, and sodium lactate was more effective.

The TVBN values in beef samples during storage at $4{ }^{\circ} \mathrm{C}$ are given in Figure 1b. The initial TVB-N values were $7.18 \mathrm{mg} / 100 \mathrm{~g}$, $6.55 \mathrm{mg} / 100 \mathrm{~g}$ and $7.53 \mathrm{mg} / 100 \mathrm{~g}$ in Group C, Group SL and Group NA, respectively, which were all lower than $10 \mathrm{mg} / 100 \mathrm{~g}$ and indicative of good meat quality (Wang et al., 2021; Tian et al., 2017). However, a significant $(\mathrm{p}<0.05)$ different increase patterns of TVB-N contents was presented in control and preservative treatment along with storage. The TVB-N levels in Group C increased sharply and reached to $19.71 \mathrm{mg} / 100 \mathrm{~g}$ on the $3^{\text {rd }}$ day. In contrast, the TVB-N levels increased slowly both in Group SL and Group NA, and reached to $15.80 \mathrm{mg} / 100 \mathrm{~g}$ on the $6^{\text {th }}$ day and $14.77 \mathrm{mg} / 100 \mathrm{~g}$ on the $5^{\text {th }}$ day, respectively. The TVB-N as a direct quality indicator of meat freshness is positively correlated with the growth of spoilage bacteria (Chen et al., 2019), which is mainly composed of ammonia, amine and trimethylamine from microorganisms and enzyme activity (Lu et al., 2015). Referring to National Food Safety Standard of China (GB 270-2016), $15 \mathrm{mg} / 100 \mathrm{~g}$ in TVBN content was set as the upper limit for fresh level (Qiao et al., 2017). According to the threshold ( $\leq 15 \mathrm{mg} / 100 \mathrm{~g}$ ), the Group C, Group SL and Group NA reached the rejection level on the $3^{\text {rd }}, 6^{\text {th }}$ and $5^{\text {th }}$ day, respectively, indicating that both sodium lactate and Natamycin treatment contributed to shelf-life extension of chilled beef. Bacterial activity and endogenous enzymes may be responsible for the increase of TVB-N values (Cai et al., 2011). Therefore, the low TVBN level in Group SL and Group NA may be attribute to antibacterial activity (Li et al., 2019). Indeed, the results of TVBN were well agreement with the results of microbiological analyses in this study. Moreover, these results were consistent with those studies by Liu et al. (2020) and Schelegueda et al. (2016), who reported that sodium lactate and Natamycin had superior effects on inhibiting the TVB-N growth.

The color parameters $L *, a *$, and $b *$ values of beef samples during storage at $4{ }^{\circ} \mathrm{C}$ are shown in Table 1 . A significant $(\mathrm{p}<0.05)$ different change in color parameters was displayed in the control and preservative treatment along with storage. Meat color has been acknowledged as a critical indicator for consumers to evaluate meat quality and make a purchase decision, and a bright red color is considered a positive attribute for freshness and superior quality of beef (Holman et al., 2016). According to relationship between colorimetric evaluation and consumer-defined beef color acceptability, when $\mathrm{a}^{*}<14.5$, the beef color was considered desirable. In this study, the $\mathrm{a}^{*}$ value of Group C decreased to 14.57 and reached the rejection level on the $4^{\text {th }}$ day, while the $\mathrm{a}^{*}$ value in Group SL stayed above this threshold $\left(a^{*}>14.5\right)$ for the entire storage period with a range from 24.05 to 33.05 . Natamycin had no significant positive impact on $\mathrm{a}^{\star}$ value of chilled beef. These results revealed that sodium lactate was conducive to against discoloration, which was in well agreement with the previous experimental studies reported by Liu et al. (2020). Whereas, Natamycin exhibited no contribute to color protection. Thus, sodium lactate as preservative has a positive effect on slowing down the rate of discoloration and is conducive to meat color stability. The discoloration is firmly associated with the oxidation-reduction status and the amount of oxygen bound of myoglobin. The conversion of oxidation and reduction states is mainly dependent upon the Nicotinamide adenine dinucleuotide (NADH) levels which has good anti-oxidation effect on myoglobin oxidation, resulting that $\mathrm{Fe}^{+3} \mathrm{MetMb}$ would be reduced to $\mathrm{Fe}^{+2} \mathrm{OMb}$ which shows a bright red color for beef. Thus, we suggest that the color stability efficacy by sodium lactate are based on the increasing amount of NADH through in the previous step of gluconeogenesis pathway, that is, lactic acid $\left(\mathrm{CH}_{3} \mathrm{CHOHCOOH}\right)$ is catalyzed to pyruvic acid $\left(\mathrm{CH}_{3} \mathrm{COCOOH}\right)$ by Lactate Dehydrogenase (LDH-B) in mitochondrion and cytoplasm of muscle tissue. Thus, sodium lactate addition not only effectively maintains the color stability, but also improves the brightness and redness, showing a better color acceptance for beef. Therefore, sodium lactate as a potential prime bio-preservative will be applied into meat industry against discoloration of fresh or chilled meat during transportation and storage.

\subsection{Comparative effects on inhibition of microbial growth of chilled beef during storage}

Five principal microbiological indicators, namely bacterial TVC counts, LAB counts, Brochothrix spp. counts, Pseudomonas spp. counts and Enterobacteriaceae counts, were used to evaluate the microbial quality. The results of bacterial enumeration of all

Table 1. Comparative effects between sodium lactate and Natamycin on the instrumental color values of beef samples during storage at $4{ }^{\circ} \mathrm{C}$.

\begin{tabular}{|c|c|c|c|c|c|c|c|c|}
\hline \multirow{2}{*}{ Attribute } & \multirow{2}{*}{ samples } & \multicolumn{7}{|c|}{ Storage time (days) } \\
\hline & & 1 & 2 & 3 & 4 & 5 & 6 & 7 \\
\hline \multirow[t]{3}{*}{$L^{*}$} & Group C & $32.60^{\mathrm{Bbc}}$ & $36.86^{\mathrm{Aa}}$ & $32.99^{\mathrm{Abc}}$ & $32.27^{\mathrm{Abc}}$ & $33.91^{\mathrm{Bb}}$ & $32.19^{\mathrm{Bbc}}$ & $31.27^{A c}$ \\
\hline & Group SL & $30.57^{\mathrm{Cb}}$ & $33.29^{\mathrm{Ba}}$ & $30.12^{\mathrm{Bb}}$ & $31.90^{\mathrm{Aa}}$ & $32.26^{\mathrm{Ca}}$ & $32.18^{\mathrm{Ba}}$ & $33.74^{\mathrm{Aa}}$ \\
\hline & Group NA & $35.83^{\mathrm{Aa}}$ & $35.27^{\mathrm{Aa}}$ & $32.98^{\mathrm{Ac}}$ & $33.00^{\mathrm{Ac}}$ & $35.73^{\mathrm{Aa}}$ & $34.47^{\mathrm{Ab}}$ & $30.55^{\mathrm{Ad}}$ \\
\hline \multirow[t]{3}{*}{$a^{*}$} & Group C & $25.39^{\mathrm{Aa}}$ & $26.53^{\mathrm{Aa}}$ & $18.09^{\mathrm{Bb}}$ & $14.57^{\mathrm{Cc}}$ & $13.41^{\mathrm{Bc}}$ & $12.84^{\mathrm{Bcd}}$ & $10.88^{\mathrm{Bd}}$ \\
\hline & Group SL & $26.39^{\mathrm{Af}}$ & $28.10^{\text {Adf }}$ & $33.05^{\mathrm{Aa}}$ & $31.27^{\mathrm{Ab}}$ & $29.15^{\text {Acd }}$ & $30.28^{\mathrm{Abc}}$ & $24.05^{\mathrm{Ag}}$ \\
\hline & Group NA & $25.32^{\mathrm{Ab}}$ & $28.09^{\mathrm{Aa}}$ & $19.01^{\mathrm{Bc}}$ & $16.90^{\mathrm{Bd}}$ & $13.17^{\mathrm{Be}}$ & $10.11^{\mathrm{Cf}}$ & $9.24^{\mathrm{Bf}}$ \\
\hline \multirow[t]{3}{*}{$b^{*}$} & Group C & $-2.51^{\mathrm{Ad}}$ & $0.38^{\mathrm{Ac}}$ & $2.00^{\mathrm{Abc}}$ & $2.06^{\mathrm{Ab}}$ & $3.36^{\mathrm{Aa}}$ & $1.02^{\mathrm{Bc}}$ & $-2.64^{\mathrm{Bd}}$ \\
\hline & Group SL & $-2.55^{\mathrm{Ac}}$ & $-0.69^{\mathrm{Bb}}$ & $0.33^{\mathrm{Bab}}$ & $0.49^{\mathrm{Bab}}$ & $1.08^{\mathrm{Ba}}$ & $0.49^{\mathrm{Bab}}$ & $0.24^{\text {Aab }}$ \\
\hline & Group NA & $-3.06^{\mathrm{Ae}}$ & $0.05^{\mathrm{Ad}}$ & $0.51^{\mathrm{Bc}}$ & $1.15^{\mathrm{ABc}}$ & $3.78^{\mathrm{Aa}}$ & $2.57^{\mathrm{Ab}}$ & $0.3^{\mathrm{Ac}}$ \\
\hline
\end{tabular}

a-g significantly different within the same type of sample after storage time of $1,2,3,4,5,6$ and 7 days $(\mathrm{p}<0.05)$. A-C significantly different between type of sample at the same storage time $(\mathrm{p}<0.05)$. 
samples during storage are shown in Figure 2. The Enterobacteriaceae was not detected in all samples through the storage $\left(\log _{10} \mathrm{CFU} / \mathrm{g}\right.$ $<1)$. The initial bacterial TVC counts in all beef samples was approximately $4.0 \log _{10} \mathrm{CFU} / \mathrm{g}$, indicating a good hygienic quality of tested beef samples. As storage time extended, the bacterial TVC counts in Group C markedly increased and reached to $5.95 \log \mathrm{CFU} / \mathrm{g}$ on the $3^{\text {rd }}$ day, while the bacterial TVC counts in Group SL and Group NA increased slowly and reached to $5.47 \log _{10} \mathrm{CFU} / \mathrm{g}$ and $4.85 \log _{10} \mathrm{CFU} / \mathrm{g}$ on $5^{\text {th }}$ day, respectively. It has been reported that when TVC counts reach $7 \log _{10} \mathrm{CFU} / \mathrm{g}$ the microbial shelf-life should be considered to have ended and the beef is unacceptable, and which is the upper microbiological limit for good quality fresh meat as defined by the International Commission on Microbiological Specifications for Foods (ICMSF). In this study, the bacterial TVC counts in Group C, Group SL and Group NA reached to above $7.0 \log _{10} \mathrm{CFU} / \mathrm{g}$ on the $4^{\text {th }}, 7^{\text {th }}$ and $8^{\text {th }}$ day, respectively. Thus, both sodium lactate and Natamycin have a positive effect on microbial shelf-life extension and Natamycin exhibited a better antibacterial efficacy. Likewise, except for LAB growth, the growths of Brochothrix spp. and Pseudomonas spp. were significantly inhibited $(\mathrm{p}<0.05)$ both by sodium lactate and Natamycin, and Pseudomonas spp. and Brochothrix spp. were trace detected $\left(\log _{10} \mathrm{CFU} / \mathrm{g}<2\right)$ both in Group SL and Group NA. Moreover, Enterobacteriaceae was not detected in all samples. In contrast, both Brochothrix spp. and Pseudomonas spp. were detected $\left(\log _{10} \mathrm{CFU} / \mathrm{g}>2\right)$ in Group C. The growth of microorganisms, especially for spoilage bacteria, is a critical factor for beef quality deterioration (Mills et al., 2014). As a result, both the sodium lactate and Natamycin usage could have a significant effect on the antimicrobial activity and Natamycin displayed a better antimicrobial activity, which are conducive to hygiene levels improvement in fresh beef during storage at $4{ }^{\circ} \mathrm{C}$.

\subsection{Comparative effects on bacterial community composition of chilled beef during storage}

The relative abundances of the top 10 phyla in all samples at different times of storage are shown in Figure 3, in which Proteobacteria with above $90 \%$ of the relative abundance and Firmicutes with about $1.2 \%$ of the relative abundance were the dominant phyla (the relative abundances $>1 \%$ ) in all of the samples during storage at $4{ }^{\circ} \mathrm{C}$ for 7 days. At the beginning
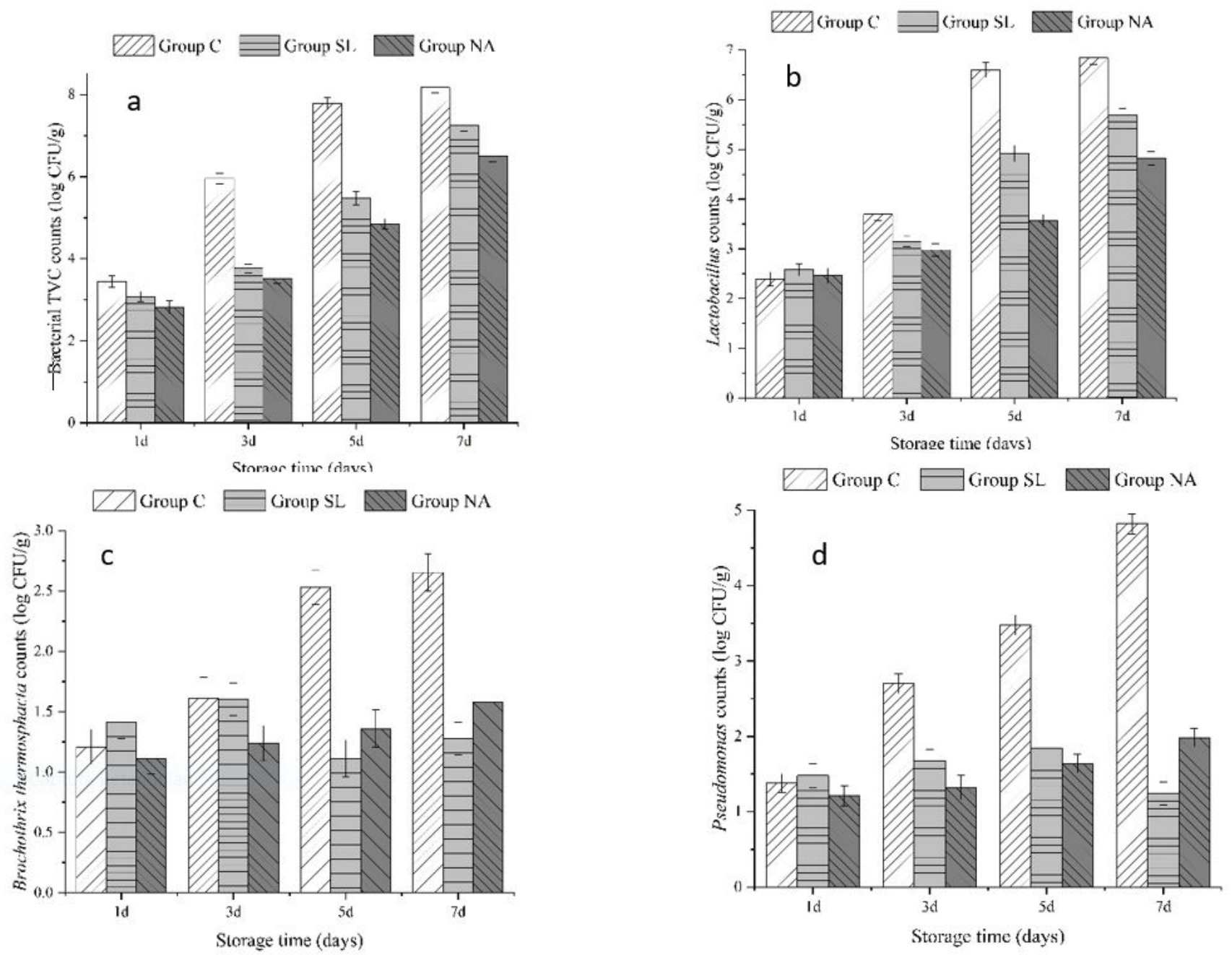

Fig. 2. Comparative effects between sodium lactate and Natamycin on on Total viable counts (TVC) (a) and Lactic acid bacterial (LAB ${ }^{\star}$ counts (b), Brochothrix spp. counts (c) and Pseudomonas spp. counts (d). 


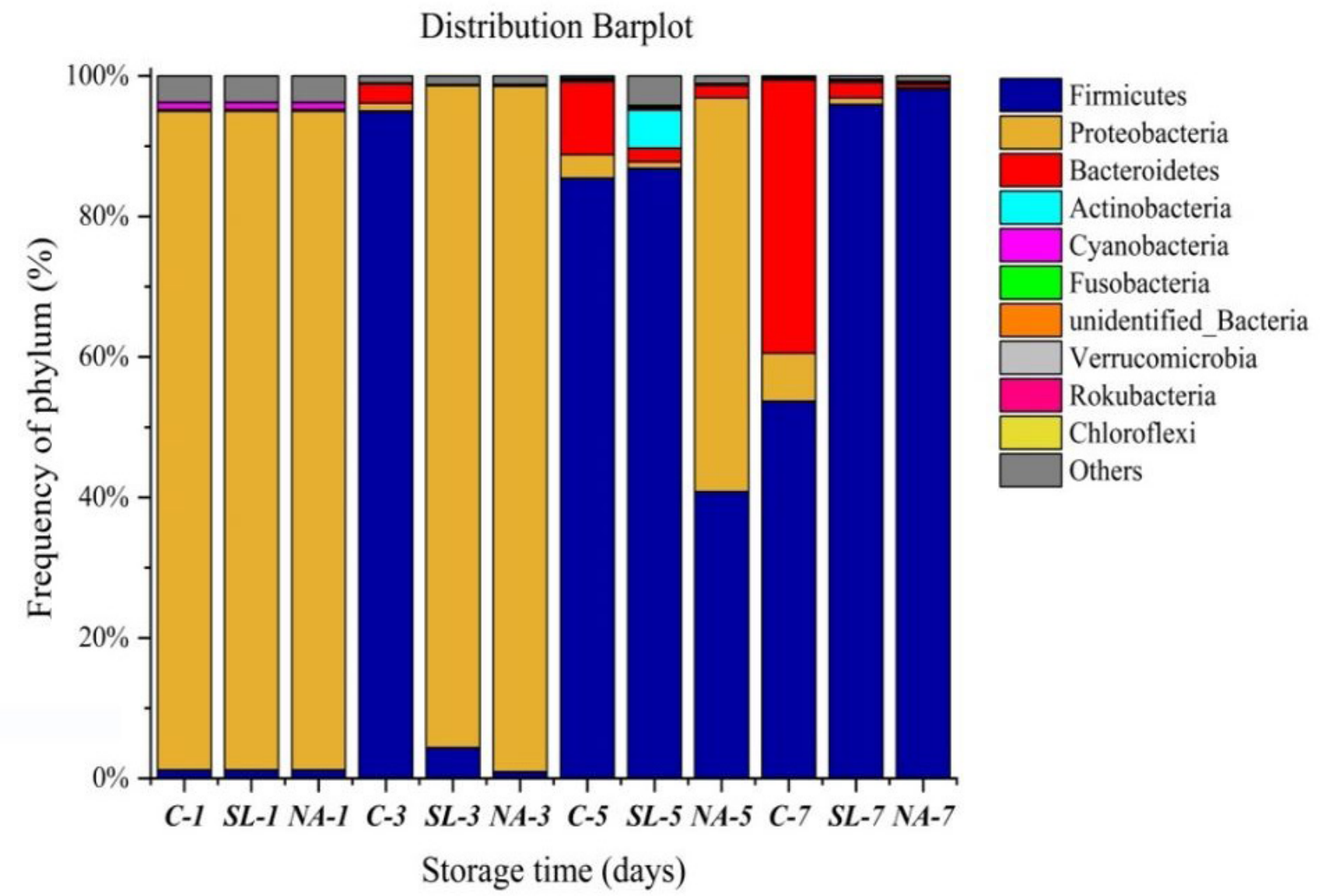

Fig. 3 Comparative effects between sodium lactate and Natamycin on bacterial community composition of chilled beef at phylum level during storage at $4^{\circ} \mathrm{C}$ on $1^{\text {st }}, 3^{\text {rd }}, 5^{\text {th }}$ and $7^{\text {th }}$ day.

of storage, Proteobacteria was the most predominant phylum with $93.7 \%$ of the relative abundance followed by Firmicutes in Group C, but Proteobacteria substantially decreased sharply from $93.7 \%$ to $1.1 \%$, and Firmicutes rapidly became the most dominant phylum with $94.9 \%$ of the relative abundance on the $3^{\text {rd }}$ day. Correspondingly, Proteobacteria as the most predominant phylum remained stable in a range from $97.6 \%$ to $93.6 \%$ for 3 days, and then the abundance of Proteobacteria decreased sharply to $0.92 \%$ and $56.1 \%$ in Group SL and Group NA on the $5^{\text {th }}$ day, respectively, and was replaced by Firmicutes.

At the level of genus, the relative abundances (above 1\%) of bacteria (top 10) in all samples at different times of storage are given in Figure 4. Initially, Ralstoni spp. was the most predominant bacteria in all beef samples with a $93.2-93.5 \%$ of relative abundance, and the amount of Lactococcus spp. was trace and lower than $1 \%$. The succession of the bacterial community of beef was significantly influenced $(\mathrm{p}<0.05)$ both by sodium lactate and Natamycin treatment. In Group C, Ralstoni spp. was the predominant bacteria, accounting for $93.2 \%$ on the first day. Subsequently, it decreased to $0.1 \%$, and Lactococcus spp. suddenly reached a maximum of $81.4 \%$ on the $3^{\text {rd }}$ day and then gradually decreased to $43.15 \%$ on the $7^{\text {th }}$ day. Meanwhile, Myroides spp. showed an increase from the third day and became predominant with a relative abundance of $37.7 \%$ on the $7^{\text {th }}$ day. Moreover, Serratia spp. was observed on $7^{\text {th }}$ day, accounting for $4.8 \%$ of the total abundance. Instead, both in Group SL and Group NA, Lactobacillus spp. (33.9\%-78.7\%) and Weissella spp. (4.5\%-18.1\%) underwent a dramatic increase and dominated during the middle and late stage of the storage period (5-7 days). Moreover, Serratia spp. was nearly undetectable both in Group SL and Group NA at all storage time points.

In Group SL and Group NA, Ralstoni spp. predominated at the initial stage of storage and was displaced by Lactobacillus spp. and Weissella spp. during the middle and late stage of the storage period, which was well line with the results reported by Liu et al. (2020). Both Lactobacillus spp. and Weissella spp. can inhibit the spoilage bacteria growth such as Serratia spp. and Pseudomonas spp., due to their antibacterial activity and anti-oxidative activities (Yadav et al., 2020). Serratia spp. as the representatives' genus of psychrotrophic Enterobacteriaceae and Pseudomonas spp. with high spoilage potential (Holman et al., 2017) are easy to cause deterioration of fresh beef or pork under chilled conditions. These results revealed that both sodium lactate and Natamycin treatment was conducive that Lactobacillus spp. and Weissella spp. became the dominant bacteria, resulting in competitive inhibition the growth of Serratia spp. and Ralstoni spp. which is a branch of Pseudomonas spp. Indeed, Serratia spp. was almost undetectable in Group SL and Group NA during the whole storage period. Whereas, a small amount of Serratia spp. (0.24\%) was detected on the $5^{\text {th }}$ day and a high level 


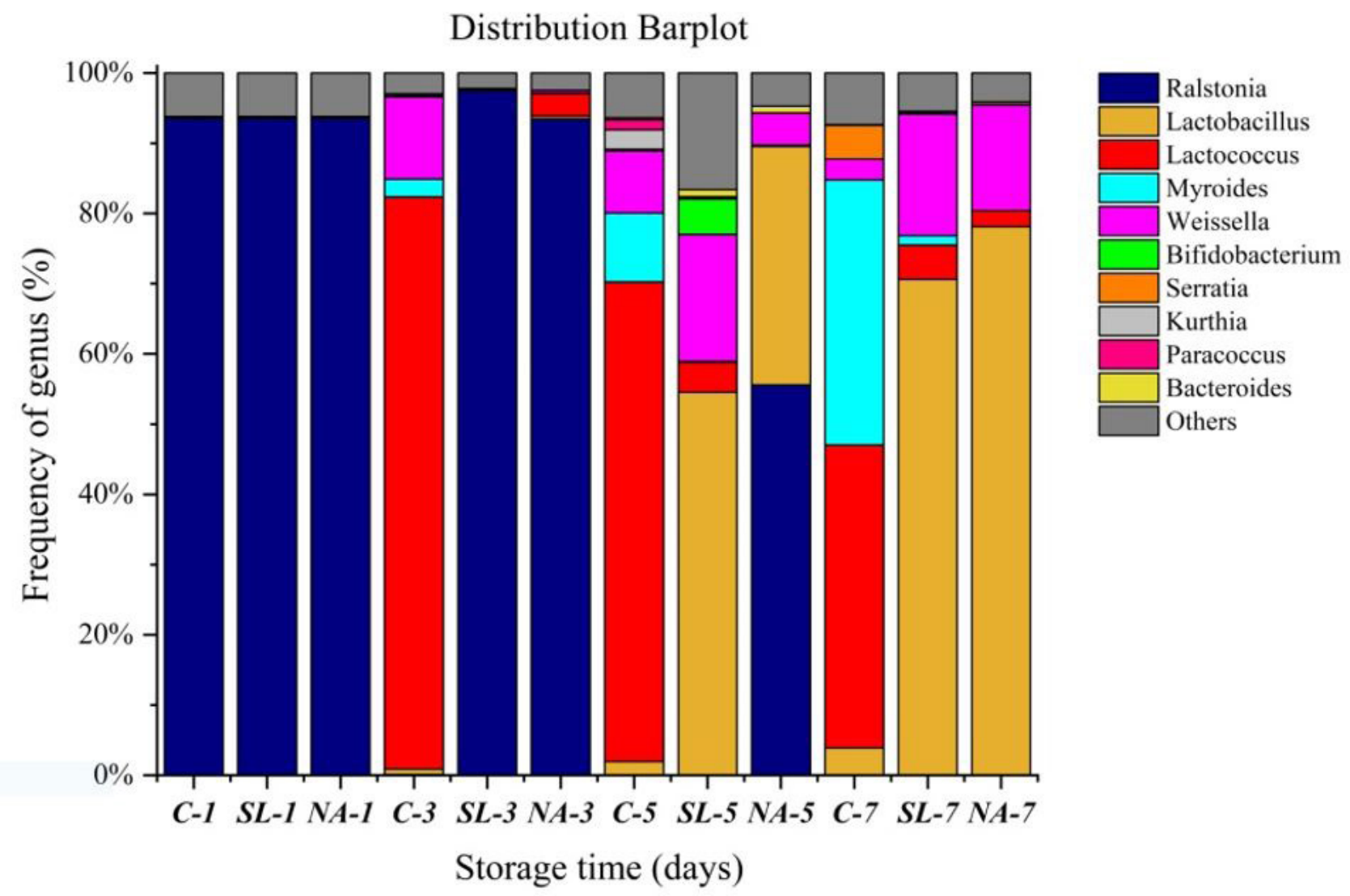

Fig. 4 Comparative effects between sodium lactate and Natamycin on bacterial community composition of chilled beef at genus level during storage at $4^{\circ} \mathrm{C}$ on $1^{\text {st }}, 3^{\text {rd }}, 5^{\text {th }}$ and $7^{\text {th }}$ day.

(4.79\%) was presented on the $7^{\text {th }}$ day. Furthermore, combined with the findings of Brochothrix spp. counts, Pseudomonas spp. counts and Enterobacteriaceae counts, both sodium lactate and Natamycin treatment was conducive to controlling the rate of proliferation spoilage bacteria, which maybe attribute to interspecific competition produced by Lactobacillus spp. together with their bacteriocins products.

These results suggested that both sodium lactate and Natamycin treatment are effective ways to obtain reliable shelf-life of fresh beef by hygiene levels improvement during storage at $4{ }^{\circ} \mathrm{C}$. However, further study to verify this hypothesis is required and their direct relationship and effects on the final shelf-life need further exploration.

\subsection{Comparative effects on sensory evaluation of chilled beef during storage}

The appearance of all chilled beef samples stored at $4{ }^{\circ} \mathrm{C}$ is shown in Figure 5. An acceptable appearance presented in all samples during the first 3 days. On the $4^{\text {th }}$ day, the appearance of Group C and Group NA was undesirable, while the appearance of Group SL was still with a good acceptance until on the $7^{\text {th }}$ day.
Based on the results of the sensory score radar map as shown in Figure 6 the distance of the 5 evaluation indexes (color, odor, texture, appearance and viscosity) in Group C (Figure 6a) between D3 and D4 in the radar map was the largest, indicating that the sensory changes of meat are the most obvious from the $3^{\text {th }}$ to $4^{\text {th }}$ day, and began to become no-fresh. In contrast, the distance of the 5 evaluation indexes in Group SL (Figure 6b) and Group NA (Figure 6c) between D6 and D7, D4 and D5, respectively, was the largest, indicating that the sensory changes of beef are the most obvious from the $6^{\text {th }}$ to $7^{\text {th }}$ day, $4^{\text {th }}$ to $5^{\text {th }}$ day, respectively, and began to become no-fresh. These results are well line with the result of color. According to the sensory evaluation, the sodium lactate prolonged the shelf life of chilled beef by $3-4$ days and maintained higher sensory acceptability. Whereas, Natamycin treatment had no significant contribution to sensory quality improvement of chilled beef.

\subsection{Comparative efficacy on extending shelf life}

Preservation technology can be used to extend the shelf life of fresh beef avoiding a wastage problem. In this study, sodium lactate and Natamycin which have been approved by FDA as a safe food addictive were applied to retain freshness of chilled 


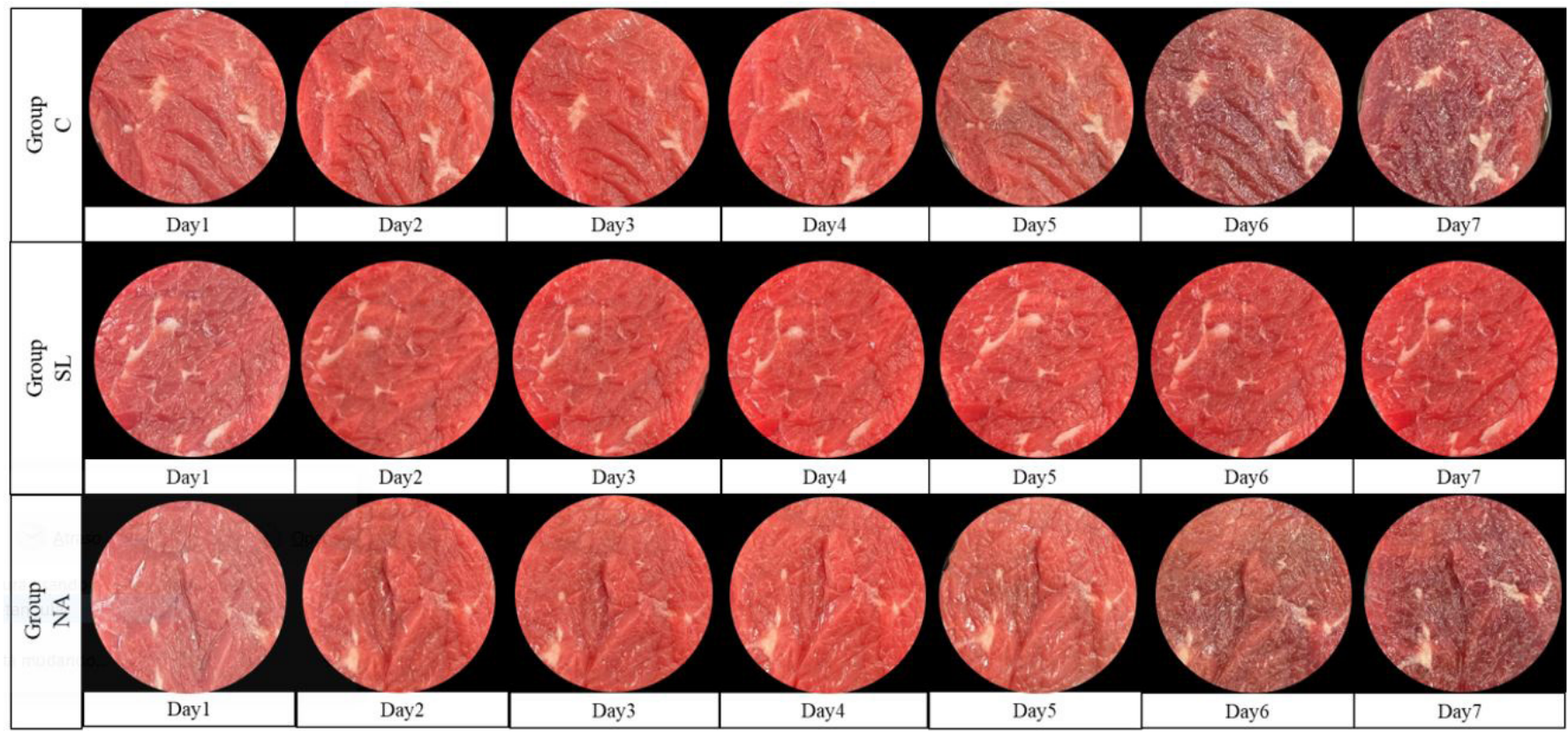

Fig. 5. Comparative effects between sodium lactate and Natamycin on on color appearance of beef samples during storage at $4^{\circ} \mathrm{C}$ for 7 days.
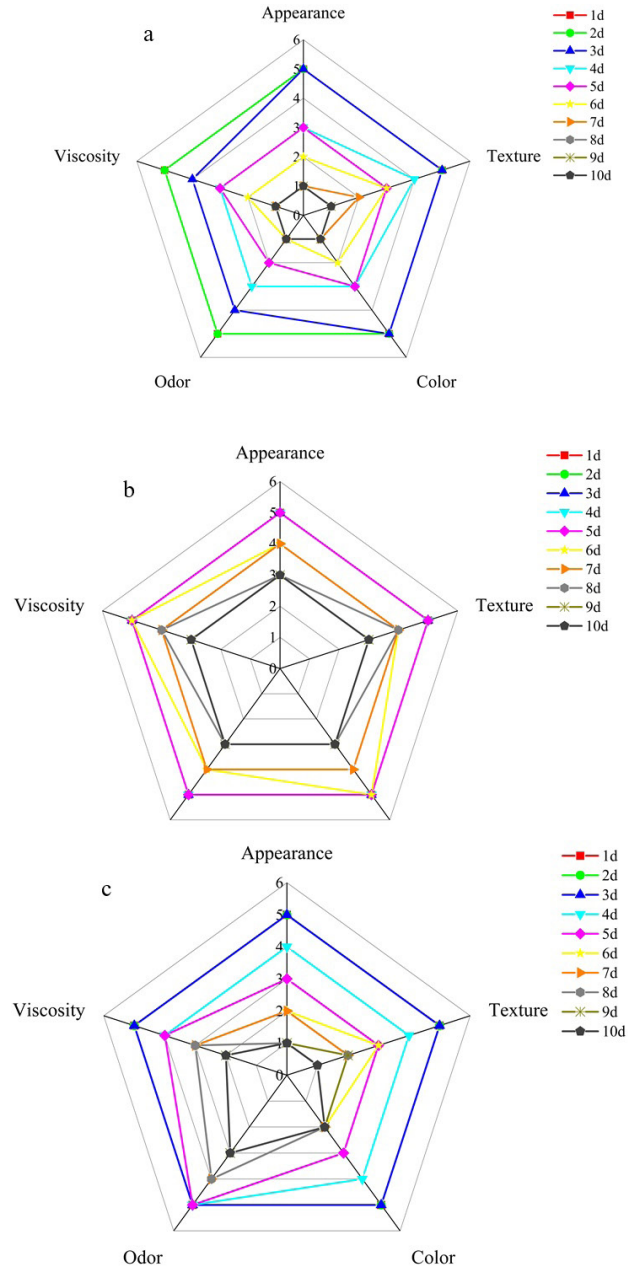

Fig. 6 The sensory evaluation including color, odor, texture, appearance and viscosity of Group C (a), Group SL (b) and Group NA (c) during storage at $4^{\circ} \mathrm{C}$ for 10 days. beef during storage at $4^{\circ} \mathrm{C}$ to extend the shelf life. Both sodium lactate and Natamycin effectively maintained the $\mathrm{pH}$ stabilization, while the $\mathrm{pH}$ in the control fluctuated violently.

The TVB-N levels reached the rejection level ( $\leq 15 \mathrm{mg} / 100 \mathrm{~g})$ in chilled beef treated by sodium lactate and Natamycin on the $6^{\text {th }}$, and $5^{\text {th }}$ day, respectively. In contrast, the TVBN levels nearly reached the rejection level on the $3^{\text {rd }}$ day in the control. Combined appearance color with instrumental color, undesirable acceptance color of the control displayed on the $4^{\text {th }}$ day, while acceptance color presented in beef treated by sodium lactate until the $7^{\text {th }}$ day. However, acceptance color exhibited in beef treated by Natamycin for 4 days. Furthermore, the bacterial TVC counts in beef treated by sodium lactate and Natamycin were above $7.0 \log _{10} \mathrm{CFU} / \mathrm{g}$ on $6^{\text {th }}$ and $7^{\text {th }}$ day, respectively. In contrast, the bacterial TVC counts in the control reached to above $7.0 \log _{10} \mathrm{CFU} / \mathrm{g}$ on the $5^{\text {th }}$ day. As a result, through comprehensive analysis of these indexes, namely $\mathrm{pH}, \mathrm{TVB}-\mathrm{N}$, color and bacterial TVC counts, the shelf life of chilled beef stored at $4{ }^{\circ} \mathrm{C}$ was no more than 3 days, while the shelf life of chilled beef treated by sodium lactate reached 6 days. Natamycin displayed a little positive efficacy on shelf life extension of chilled beef. These results indicate that sodium lactate can effectively prolong the shelf life of fresh beef stored at $4{ }^{\circ} \mathrm{C}$, suggesting that sodium lactate as bio-preservative is more suitable for keeping freshness of chilled meat compared with Natamycin.

\section{Conclusions}

Based on the comprehensive analysis of these indexes, namely $\mathrm{pH}, \mathrm{TVBN}$, color and bacterial TVC counts, the acceptable shelf life of chilled beef treated by sodium lactate and Natamycinstored at $4^{\circ} \mathrm{C}$ reached 6 days and 4 days, respectively. Whereas, chilled beef without preservative treatment was acceptable organoleptically for 3 days. Sodium lactate exhibited a remarkable efficacy against discoloration. 
According to the five principal microbiological indicators, namely TVC, LAB, Brochothrix spp., Pseudomonas spp. and Enterobacteriaceae counts, both the sodium lactate and Natamycin were is conducive to hygiene levels improvement, and Natamycin displayed a better antibacterial efficacy. Specifically, the TVC counts reached to above $7.0 \log _{10} \mathrm{CFU} / \mathrm{g}$ on $4^{\text {th }}$ day in the control, while chilled beef treated by sodium lactate and Natamycin reached to above $7.0 \log _{10} \mathrm{CFU} / \mathrm{g}$ on $6^{\text {th }}$ and $7^{\text {th }}$ day, respectively. The growths of Brochothrix spp., Pseudomonas spp. and Enterobacteriaceae were significantly inhibited $(\mathrm{p}<0.05)$ both by sodium lactate and Natamycin.

According to these results from high throughput sequencing data, the proliferation of Serratia spp. with high spoilage potential was completely controlled both by sodium lactate and Natamycin. Bacterial community and succession in chilled beef were significantly affected both by sodium lactate and s Natamycin. Lactobacillus spp. and Weissella spp. sharply displaced the Ralstoni spp. with high spoilage potential and became the predominant bacteria both in sodium lactate and Natamycin treatment, which maybe attribute to interspecific competition produced by Lactobacillus spp. together with their bacteriocins products.

As a result, sodium lactate displayed a remarkable efficacy against discoloration and antibacteria activity, resulting in delaying spoilage and prolonging shelf life of fresh beef during chilled storage. Natamycin has a remarkable antibacterial efficacy but a little efficacy against discoloration. Thus, through comparative efficacy of sodium lactate and Natamycin against discoloration and spoilage, sodium lactate as a bio-preservative is suggested to be used for maintaining freshness of fresh beef stored at $4^{\circ} \mathrm{C}$.

\section{Conflict of interest}

The authors declare that there is no conflict of interest.

\section{Acknowledgements}

This work was supported by the National Natural Science Foundation of China (31772093), Research Fund Project of Chengdu Agricultural College (20ZR110), Open Fund of Sichuan Key Laboratory for Solid State Fermentation Resources Utilization (2018gtj001; 2019GTJ010) and Key Laboratory of Collaborative Control and Remediation of Soil and Water Pollution (GHBK-003). The authors thank Novogene Biotech for technical assistance in carrying out the analyses.

\section{References}

Cai, J., Chen, Q., Wan, X., \& Zhao, J. (2011). Determination of total volatile basic nitrogen (TVB-N) content and warner-bratzler shear force (WBSF) in pork using fourier transform near infrared (FTNIR) spectroscopy. Food Chemistry, 126(3), 1354-1360. http://dx.doi. org/10.1016/j.foodchem.2010.11.098.

Chen, X., Zhang, Y. M., Yang, X. Y., Hopkins, D. L., Zhu, L. X., Dong, P. C., Liang, R. R., \& Luo, X. (2019). Shelf-life and microbial community dynamics of super-chilled beef imported from Australia to China. Food Research International, 120, 784-792. http://dx.doi.org/10.1016/j. foodres.2018.11.039. PMid:31000298.

Chen, X., Zhu, L. X., Liang, R. R., Mao, Y. W., Hopkins, D. L., Li, K., Dong, P. C., Yang, X. Y., Niu, L. B., Zhang, Y. M., \& Luo, X. (2020).
Shelf-life and bacterial community dynamics of vacuum packaged beef during long-term super-chilled storage sourced from two Chinese abattoirs. Food Research International, 130, 108937. http:// dx.doi.org/10.1016/j.foodres.2019.108937. PMid:32156384.

Choi, S. H., \& Chin, K. B. (2003). Evaluation of sodium lactate as a replacement for conventional chemical preservatives in comminuted sausages inoculated with Listeria monocytogenes. Meat Science, 65(1), 531-537. http://dx.doi.org/10.1016/S0309-1740(02)00245-0. PMid:22063246.

Edgar, R. C. (2010). Search and clustering orders of magnitude faster than BLAST. Bioinformatics (Oxford, England), 26(19), 2460-2461. http://dx.doi.org/10.1093/bioinformatics/btq461. PMid:20709691.

Holman, B. W. B., Mao, Y., Coombs, C. E. O., Van de Ven, R. J., \& Hopkins, D. L. (2016). Relationship between colorimetric (instrumental) evaluation and consumer-defined beef colour acceptability. Meat Science, 121, 104-106. http://dx.doi.org/10.1016/j.meatsci.2016.05.002. PMid:27294520.

Holman, B. W., van de Ven, R. J., Mao, Y., Coombs, C. E., \& Hopkins, D. L. (2017). Usinginstrumental (CIE and reflectance) measures to predict consumers' acceptance of beef colour. Meat Science, 127, 57 62. http://dx.doi.org/10.1016/j.meatsci.2017.01.005. PMid:28130985.

Li, Y., Tang, X., Shen, Z., \& Dong, J. (2019). Prediction of total volatile basic nitrogen (TVB-N) content of chilled beef for freshness evaluation by using viscoelasticity based on airflow and laser technique. Food Chemistry, 287, 126-132. http://dx.doi.org/10.1016/j. foodchem.2019.01.213. PMid:30857681.

Liu, Y., Zhang, F. X., Zhu, B. W., Ruan, X. R., Yi, X. M., Li, J., Gao, Y. Y., \& Hui, G. H. (2020). Effect of sodium lactate coating enriched with nisin on beef strip loins (M. Longissimus lumborum) quality during cold storage and electronic nose rapid evaluation. Journal of Food Measurement and Characterization, 14(6), 2998-3009. http:// dx.doi.org/10.1007/s11694-020-00548-4.

Liu, Y., Zhao, H., Huang, M., Chen, X., Wang, X., Fang, Y., \& Zhang, Y. (2018). The effects of photoperiod and nutrition on duckweed (Landoltia punctata) growth and starch accumulation. Industrial Crops and Products, 115, 243-249. http://dx.doi.org/10.1016/j. indcrop.2018.02.033.

Lu, S. L., Ji, H., Wang, Q. L., Li, B. K., Li, K. X., Xu, C. J., \& Jiang, C. H. (2015). The effects of starter cultures and plant extracts on the biogenic amine accumulation in traditional Chinese smoked horsemeat sausages. Food Control, 50, 869-875. http://dx.doi. org/10.1016/j.foodcont.2014.08.015.

Magrinyà, N., Terjung, N., Loeffler, M., Gibis, M., Bou, R., \& Weiss, J. (2015). Influence of fat addition on the antimicrobial activity of sodium lactate, lauric arginate and methylparaben in minced meat. International Journal of Food Microbiology, 215, 86-94. http://dx.doi. org/10.1016/j.ijfoodmicro.2015.08.017. PMid:26344644.

Mancini, R. A., Ramanathan, R., Suman, S. P., Konda, M. K., Joseph, P., Dady, G. A., Naveena, B. M., \& López-López, I. (2010). Effects of lactate and modified atmospheric packaging on premature browning in cooked ground beef patties. Meat Science, 85(2), 339-346. http:// dx.doi.org/10.1016/j.meatsci.2010.02.001. PMid:20374909.

Mills, J., Donnison, A., \& Brightwell, G. (2014). Factors affecting microbial spoilage and shelf-life of chilled vacuum-packed lamb transported to distant markets: a review. Meat Science, 98(1), 71-80. http://dx.doi.org/10.1016/j.meatsci.2014.05.002. PMid:24875594.

Qiao, L., Tang, X., \& Dong, J. (2017). A feasibility quantification study of total volatile basic nitrogen (TVB-N) content in duck meat for freshness evaluation. Food Chemistry, 237, 1179-1185. http://dx.doi. org/10.1016/j.foodchem.2017.06.031. PMid:28763967. 
Quast, C., Pruesse, E., Yilmaz, P., Gerken, J., Schweer, T., Yarza, P., Peplies, J., \& Glöckner, F. O. (2013). The SILVA ribosomal RNA gene database project: Improved data processing and web-based tools. Nucleic Acids Research, 41(Database issue), D590-D596. PMid:23193283.

Sallam, K. I., \& Samejima, K. (2004). Microbiological and chemical quality of ground beef treated with sodium lactate and sodium chloride during refrigerated storage. Lebensmittel-Wissenschaft + [i.e. und] Technologie. Food science + technology. Science + technologie alimentaire, 37(8), 865-871. http://dx.doi.org/10.1016/j. lwt.2004.04.003. PMid:17330155.

Schelegueda, L. I., Delcarlo, S. B., Gliemmo, M. F., \& Campos, C. A. (2016). Effect of antimicrobial mixtures and modified atmosphere packaging on the quality of Argentine hake (Merluccius hubbsi) burgers. Lebensmittel-Wissenschaft + Technologie, 68, 258-264. http://dx.doi.org/10.1016/j.lwt.2015.12.012.

Tian, X., Wu, W., Yu, Q., Hou, M., Gao, F., Li, X., \& Dai, R. (2017). Bacterial diversity analysis of pork longissimus lumborum following long term ohmic cooking and water bath cooking by amplicon sequencing of 16S rRNA gene. Meat Science, 123, 97-104. http:// dx.doi.org/10.1016/j.meatsci.2016.09.007. PMid:27665069.

Wang, X., Zhang, Y., Sun, J., Pan, P., Yang, L., \& Tian, T. (2021). Effects of starter culture inoculation on microbial community diversity and food safety of Chinese Cantonese sausages by high-throughput sequencing. Journal of Food Science and Technology, 58(3), 931-939. http://dx.doi.org/10.1007/s13197-020-04607-y.

Wang, X. H., Ren, H. Y., Wang, W., Bai, T., \& Li, J. X. (2015a). Evaluation of key factors influencing histamine formation and accumulation in fermented sausages. Journal of Food Safety, 35(3), 395-402. http:// dx.doi.org/10.1111/jfs.12187.

Wang, X. H., Ren, H. Y., Wang, W., Zhang, Y., Bai, T., Li, J. X., \& Zhu, W. Y. (2015b). Effects of inoculation of commercial starter cultures on the quality and histamine accumulation in fermented sausages. Journal of Food Science, 80(2), M377-M383. http://dx.doi. org/10.1111/1750-3841.12765. PMid:25588615.
Wang, X., Zhang, Y., Ren, H., \& Zhan, Y. (2018). Comparison of bacterial diversity profiles and microbial safety assessment of salami, Chinese dry-cured sausage and Chinese smoked-cured sausage by high-throughput sequencing. LWT-Food Since and Technology, 90, 108-115. http://dx.doi.org/10.1016/j.lwt.2017.12.011.

Wang, X., Ren, H., \& Zhan, Y. (2017). Characterization of microbial community composition and pathogens risk assessment in typical Italian-style salami by high-throughput sequencing technology. Food Science and Biotechnology, 27(1), 241-249. http://dx.doi.org/10.1007/ s10068-017-0200-5. PMid:30263746.

Wang, X., Wang, S., \& Zhao, H. (2019). Unraveling microbial community diversity and succession of Chinese Sichuan sausages during spontaneous fermentation by high-throughput sequencing. Journal of Food Science and Technology, 56(7), 3254-3263. http://dx.doi. org/10.1007/s13197-019-03781-y. PMid:31274892.

Yadav, B., Spinelli, A. C., Misra, N. N., Tsui, Y. Y., McMullen, L. M., \& Roopesh, M. S. (2020). Effect of in-package atmospheric cold plasma discharge on microbial safety and quality of ready-to-eat ham in modified atmospheric packaging during storage. Journal of Food Science, 85(4), 1203-1212. http://dx.doi.org/10.1111/17503841.15072. PMid:32118300.

Yang, C., Che, Y., Qi, Y., Liang, P., \& Song, C. (2017). High-throughput sequencing of viable microbial communities in raw pork subjected to a fast cooling process. Journal of Food Science, 82(1), 145-153. http://dx.doi.org/10.1111/1750-3841.13566. PMid:27871121.

Yang, C., Qi, Y., Zheng, J., Fan, X. U., Liang, P., \& Song, C. (2018). Efficacy of various preservatives on extending shelf life of vacuum-packaged raw pork during $4{ }^{\circ} \mathrm{C}$ storage. International Association for Food Protection, 81(4), 636-645. http://dx.doi.org/10.4315/0362-028X. JFP-17-423. PMid:29543526.

Zhang, Y., Li, D., Lv, J., Li, Q., Kong, C., \& Luo, Y. (2017). Effect of cinnamon essential oil on bacterial diversity and shelf-life in vacuumpackaged common carp (Cyprinus carpio) during refrigerated storage. International Journal of Food Microbiology, 249, 1-8. http://dx.doi. org/10.1016/j.ijfoodmicro.2016.10.008. PMid:28271852. 


\section{Supplementary Material}

Supplementary material accompanies this paper.

Table S1. Supplementary Table 1 Sensory scheme for evaluating the beef sample quality.

This material is available as part of the online article from https://www.scielo.br/j/cta 